\title{
Applicability Evaluation to Capital Asset Pricing Model
}

\author{
Xinzhu Li \\ Economics and Management School of Wuhan University, Wuhan, 430072 Hubei, China \\ Email:lixinzhudoctor@163.com
}

\begin{abstract}
The Capital Asset Pricing Model (CAPM), proposed by Professor William. F. Sharpe, a Nobel Prize winner in economics, is considered to be the backbone of pricing theory in modern financial market. The model is simple and practical, and mainly adopted in researches on the relationship between the expected rate of assets return and the assets investment risk, as well as the formation mechanism of equilibrium price. The Capital Asset Pricing Theory is not fully applicable to a variety of abnormalities in financial markets and the special circumstances of China's security market due to its strict assumptions and limitations in practical application. However, with the gradual improvement of China's security market, CAPM theory, by appropriate modification, will play a major role in technical analysis thereon.
\end{abstract}

Keywords-Capital Asset Pricing Model (CAPM); investment portfolio; theoretical limitations; applicability evaluation

I. Introduction to Theory of Capital Asset Pricing Model

\section{A Overview of Theory of CAPM Theory}

Capital Asset Pricing Model (CAPM), based on the investment portfolio diversification theory founded by Markowitz, was proposed in 1964 by William F. Sharpe, the Nobel Prize winner in economics in 1990. In a simple manner, CAPM depicts the relationship between asset investment returns and risks, represents the important progress and breakthrough in the field of finance, and is one of the essential theoretical foundations of modern finance. The core idea of CAPM is that, in a capital market of competitive equilibrium, non-systematic risks can be eliminated through diversification, only systemic risks, which cannot be diversified, make impact on the expected return (measured with coefficient $\beta$ ), and thus the expected return is in linear correlation with coefficient $\beta$. Since the fundamental of portfolio theory is eliminating nonsystematic risks of investors through diversification, the investors can choose the best portfolio from assets of different risk and return characteristics, to guarantee the minimum overall risk; also, they can find a investment portfolio with the maximum return under a given risk or a portfolio with the minimum risk under a given return.

\section{B Presentation of Capital Asset Pricing Model}

\section{1) Formulas of Capital Asset Pricing Model}

CAPM is mainly adopted in researches on the relationship between the expected rate of return and risk of asset in the security market as well as the formation process of equilibrium price. Its main characteristic is creating the coefficient $\beta$ to measure the market risk (systematic risk) of corporate securities. Formulas are as follows:

$$
\begin{aligned}
& \mathrm{Ri}=\mathrm{Rf}+\beta \mathrm{i}(\mathrm{RM}-\mathrm{Rf}) \\
& \beta=\operatorname{Cov}(\mathrm{Ri}, \mathrm{RM}) / \sigma^{2} \mathrm{M}
\end{aligned}
$$

$\mathrm{Ri}=$ expected return rate of security $\mathrm{i}$

$\mathrm{Rf}=$ risk-free interest rate

$\mathrm{RM}=$ expected return rate of market portfolio

$\beta \mathrm{i}=$ coefficient $\beta$ of the security $\mathrm{i}$

$\sigma=$ standard deviation of return rate of market portfolio

Coefficient $\beta$ represents the responsible sensitivity of risk from security i relative to the market risk. The expected return rate of an asset can be measured by $\beta$, the relative measurement of asset risk.

\section{2) Capital Market Line}

According to Markowitz's "E-V Analysis", when the market is in an equilibrium state, the capital market line (CML) of the best portfolio that every investor faces is shown by CML in Figure 1:

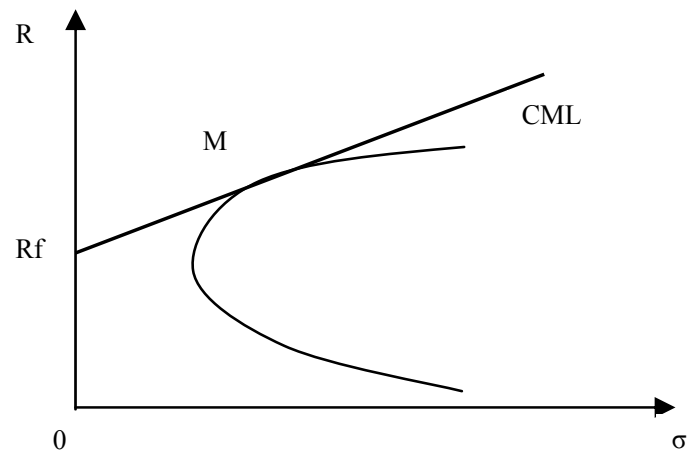

Figure 1: Module of Capital Market Line (CML)

The formula of Capital Market Line (CML) CML as follows:

$$
R i=R f+\frac{R M-R f}{\sigma M} \sigma i
$$

$\mathrm{Ri}=$ expected return rate of effective portfolio $\mathrm{i}$

$\sigma i=$ standard deviation of return of security $i$

$\mathrm{RM}=$ expected return rate of market portfolio

$\sigma \mathrm{M}=$ standard deviation of market portfolio return

Note: When all funds are invested into effective risk portfolio, Ri equals to RM.

CML has the following meanings:

1) CML is an equilibrium model, When the market is in an equilibrium state.

a) Every investor will hold a certain number of each risk security, that is, each security has a non-zero proportion at the tangency portfolio M (if no one holds the security, its 
price will continue to decrease, while its expected return rate will gradually increase; when the return rate increases to a certain level, someone will be willing to hold the security, and then its price will rebound until reaching the balance between supply and demand, and the price of the security will reach the equilibrium price).

b) The current price of each security in market will be in a balance place to supply and demand.

c) The level of risk-free interest rate just makes the total borrowed funds equal to the total lent funds, which makes the portfolio proportion at the tangency point correspond to the market portfolio proportion.

2) Any portfolio return is equal to the return of risk-free asset plus risk compensation of the portfolio (RM-Rf).

3) The pricing of portfolio is related to systemic risk, that is, the higher the systematic risk factor of the portfolio is, the more risk compensation is obtained and the higher the return is. Portfolio return is proportional to systemic risk.

4) Beta coefficient is the ratio of (standard deviation of) portfolio risk to (standard deviation of) market portfolio risk.

5) When $\beta$ is 1 , that is, the risk of portfolio selected by the investor is equal to the market portfolio risk, the portfolio is known as "neutral portfolio". When $\beta$ is higher than 1 , that is, the risk of portfolio selected by the investor is higher thanthe market portfolio risk, the portfolio is known as "radical portfolio". When $\beta$ is lower than 1 , that is, the risk of portfolio selected by the investor is lower than the market portfolio risk, the portfolio is known as "conservative portfolio".

6) The portfolios on CML are the re-combination of risk-free asset portfolio and risk asset portfolio and are all "effective portfolios", but the investor's choice of portfolio on the CML line depends on his/her risk preferences.

The result of CAPM is based on the equilibrium of the market. In reality, the points representing individual securities or portfolios are not right on the CML but distribute around it, which is considered to be the deviation of security price. The points above the CML mean the security price is underestimated, and investment in such securities will receive additional benefits; the points under the CML line mean the security price is overestimated, and the return rate of such securities will be lower than expected.

\section{Assumptions and Application Limitations of Capital Asset Pricing Model}

\section{A Assumptions}

1) Investors evaluate the asset portfolio by the expected return rate and the standard deviation during a period (To a asset or asset portfolio, the expected return rate $=($ terminal value - initial value)/ initial value; the risk is measured by the standard deviation of expected return rate).

2) Under a given investment risk, investors always seek for the maximum return rate; under a given return rate of investment, investors always try to avoid higher risk.

3) All holders have the same asset holding period, so all investors in the market can borrow money at the same risk-free interest rate.

4) The capital market is a complete market with no obstacles in the flowing of capital and information. Therefore, supposing that no investors' action can be sufficiently influential enough to the whole security market, there are no transaction costs or income taxes, and all investors are free to get all the relevant information.

5) The assets are infinitely divisible, that is, investors can buy a part of a stock which may ensure allocation of the investment at any ratio.

6) Investors have the same expectation, that is, they have the same understanding to the expected return rate, standard deviation and covariance between securities.

These assumptions restrict the market to be in an equilibrium state, where every investor faces the same effective set - optimal risk portfolio, which is an objective reality and unrelated to the risk preference of individual investors. Therefore, equilibrium relationship characteristics between the risk and return rate of each security can be obtained by observing collective behavior of all the investors in the market.

\section{B Applicability Challenges}

CAPM faces many challenges when put into practice due to the strict assumptions.

1) Under the theoretical framework of CAPM, transactions will not occur. As it is known that, transactions in the capital market occur only when market participants have different estimate to specific assets. While the assumptions of the CAPM that "reasonable person" holds "complete information" and "homogeneous expectations" make people cannot see the transaction basis in capital market under CAPM framework. For all the investors will have the same attitude towards the same asset, no transaction will occur.

2) CAPM is contradictory to the portfolio theory. The main idea of Markowitz's portfolio theory is "risk diversification", which establishes the theoretical basis for "hedging" transaction. CAPM, based on the investment portfolio theory, actually cannot reflect the true value of each asset. The reason is that the price of the asset purchased for pursuing "hedging" transaction is bound to be raised artificially and deviate from its true value. As a result, the so-called equilibrium point reflecting the true value deduced from CAPM model hardly exists.

3) With the rapid development of financial markets, abnormalities continually emerge. Such as abnormal returns associated with the scale, price-earning ratio, year-end effect, undue fluctuation, overreaction of option price, and equity premium, etc.. These abnormalities cannot be explained by CAPM.

\section{Application Value in China's Securities Market}

China's stock market is widely pervaded with motivations and phenomena of irregular operations such as speculation of investors, manipulation of securities companies and foundations, financing and expropriation of listed companies due to its immatureness. According to the testing results to effectiveness of CAPM application in China's stock market, the systematic risk coefficient cannot interpret the average revenue of China's stock market. 
Nevertheless, as this theory contains Markowitz's assets portfolio theory, and offers analysis on risk, discussion on market portfolio and its substitutes, and description on the relationship between risk and return, it is only significant in giving theoretical guidance to China's securities market.

\section{A Serious Asymmetry of Securities Information}

One important feature of an efficient market is full information publicity, through which every investor can access to all valuable information for free and the information, once publicized, will immediately influence securities prices and be rapidly reflected by securities prices, which are the reflection of their real value. There are noticeable problems with the information disclosure of China's stock market: on one hand, it is difficult to fully publicize information via normal channels due to unsound laws and regulations and technical drawbacks, e.g. information disclosure clauses (contents and time); on the other hand, inactiveness and falsity exist in information disclosure. Quite a few listed companies take information disclosure as an added burden rather than a bounden duty or a deserved right of shareholders, so they are not active in disclosing relevant information but hope to disclose information as little as possible, which makes them walk through information disclosure. Worse still, for the purpose of smooth corporate stocks issuance, some listed companies even collude with intermediary organs in over-promoting corporate images; or even disguise accounting processes and varnish financial information to inflate profits so as to worm their way into confidences from shareholders and the public; or collude with outside in speculating in stocks of their companies to mislead investors. Under this condition, investors rather than fairly access to real information but more rely on the so called "inside information", which leads to the serious deviation of securities price.

Due to the nonstandard and imperfect system of information disclosure, serious information asymmetry exists in China's securities market, which brings excess profits to information monopolists and exerts great impact on market efficiency.

\section{B Less Considerable Scale of Stock Market}

Generally, two variables reflect the market scale, i.e. the ratio of total market capitalization to GDP and the number of listed companies. The former directly reflects the importance of stock market in national economy, avoiding the impact of state economic condition; the latter indirectly reflects the supply scale of stocks in the market through the number of stock issuing bodies.

An efficient market is based on a certain scale, without which various functions of the market are difficult to be fully exerted. After the market scale expands, on one hand, investors have opportunities to conduct full portfolio to avoid risks; on the other hand, as the market competitiveness is increasingly intensive, the share price is more likely to become the real signal to reflect the value of listed companies, which is beneficial for improving the resource allocation efficiency.

\section{Speculative Ideas of Investors}

CAPM assumes that, all investors apply Markowitz's asset portfolio theory to information analysis and treatment, and they take the same attitude towards investment and on this basis reviews pricing mechanisms, thus the investors' rational decision-making is a premise for strong CAPM applicability to the realistic market. In addition, individual investors dominate China's securities market. As the majority of them lack experience especially professional knowledge, their speculative idaes are mainly featured with speculation, following declarers and relying on inside information. Their blindness in entering the market can also be seen from the market condition revealed by information and market quotations publicized on securities exchange websites all over the country. For example, most of them are engaged in short-term speculation. The capital strength of individual investors is extremely limited and the cost of information collection is always high, so it is obviously impractical to require these investors have the same comprehension on the covariance of expected return rate, standard deviation and securities price. As can be seen from analysis on the investment subjects of the foreign mature stock markets, it is institutional investors who are the important participants of securities markets. Their continuously digging information makes the share prices reflect information to the largest extent. Only institutional investors become the true dominant force of the market can the application value of CAPM be largely increased in China.

\section{Evaluation and Prospect}

\section{A Evaluation on Capital Asset Pricing Model}

CAPM deeply interprets the pricing theory of assets in equilibrium market, but even in US securities market which is regarded as the most perfect, the "relationship between risk and return" is not fully superposed with the theory. Some think the conditions assumed by CAPM are too strict to inconsistent with realities and the solution to the efficiency and necessity of equilibrium market is suspectable, however, CAPM has its unique advantages.

\section{1) Solution to General Problems in Investment Decision}

CAPM, as the milestone of asset pricing, is one of the theoretical foundations of modern financing and investment. As it can draw conclusions closest to realities via simplest and most practical approaches, it is considered as the backbone of modern price theory of money market, which is one of the main reasons for that Sharpe won the Nobel Prize in economics. Its price mode is usually used by investors of financing market to solve general problems in investment decisions.

\section{2) Offering to Investment Estimation Mechanism}

CAPM offers such a mechanism to investors that they can base their choices of multiple financial assets on systematic risks rather than total risk of assets. Investors can determine the expected return rate of complete market portfolios via authoritative aggregative index and then calculate coefficient $\beta$ of optional single asset as well as determine the risk-free return rate according to that of treasuries or other suitable government bonds.

\section{3) Simple and Specific Analysis Method}

CAPM puts the price of any kind of asset under influence of three factors, such as risk-free factor, price factor of risk and arithmetical unit of risk, and offers simple methods to solve the problem with pricing of single assets.

1) It adopts coefficient $\beta$ to determine the systematic risks contained in single asset. 
2) The model calculates the market price (RM-Rf) of risks through the concept of all market portfolios.

3) It connects the systematic risks of single asset to the market price of risks. So it provides a standard formula to calculate the single asset value under the condition of an equilibrium market.

\section{4) Drawback of Applicability}

Although CAPM is widely used in investment portfolio, it has obvious drawbacks. Firstly, such strict modeling assumptions as single time horizons of investors, the same expectations of investors on prices and efficient markets are impractical; secondly, such limitation due to imperfect development of China's capital market, as low information publicity degree, imperfect information disclosure mechanism, unreasonable investor structures and unreasonable shareholding structures of listed companies, etc., lower the practical applicability level of CAPM.

\section{B Prospect on CAPM}

Through 60 years of development, CAPM theory is increasingly mature, provided with better theoretic universality and interpretation ability to realities. Nevertheless, due to the complexity of the real world, if these theories are provided with good theoretic universality, they can poorly interpret the realities, and while if they are provided with ability of interpretation to realities, they can only make partial analysis without theoretic depth and width.
Since it was established in 1991, China's securities market has gone through rapid development, but it is still far away from complete market, and CAPM cannot be entirely applied to China's securities market. However, with its gradual improvement, CAPM theory, by appropriate modification, will play a major role in technical analysis thereon.

\section{References}

[1] William F. Sharpe, GordonJ.Alexander and Jeffery V.Bailey, translated by Zhao Xijun, etc., Investment [M], Beijing: China Renmin University Press, 1998.

[2] William D. Miller and Hu Jinglin, translated by Chen Bulin, etc., Financial Asset Appraisal [M], Beijing: Economic Science Press, 2001.

[3] Roger A. Morin and Sherry L. Jarrell, translated by Zhang Pingdan and $\mathrm{Xu}$ Jiayong, Enterprise value[M], Beijing: Enterprise Management Publishing House, 2002.

[4] Xiao Xiang and He Lin, Assets Evaluation Tutorial [M], Beijing: Tsinghua University Press, 2004.

[5] Wang Qian, Frontline Research on Behavioral Asset Pricing Model [J], Commercial Time, 2007 (31).

[6] Yi Yangping, Behavioral Finance Theory [M], Shanghai: Shanghai University of Finance and Economics Press, 2005.

[7] Zhang Shude, The Study on Behavioral Capital Asset Pricing Model Containing Fluctuation Term--Equilibrium Analysis to Investment and Consumption [J], Journal of Finance and Economics, 2005 (11).

[8] Jing Naiquan, Capital Asset Pricing Model and Commentary [J], Economists, 2000 (4) 